\title{
Coral degradation and the structure of tropical reef fish communities
}

\author{
David A. Feary*, Glenn R. Almany, Geoffrey P. Jones, Mark I. McCormick \\ ARC Centre of Excellence for Coral Reef Studies, School of Marine and Tropical Biology, James Cook University, \\ Townsville, Queensland 4811, Australia
}

\begin{abstract}
Coral reefs can be degraded by a variety of perturbations, including bleaching and predation by crown-of-thorns starfish. The combination of these disturbances has contributed to a global decline of live coral cover on reefs. While the effects of bleaching and starfish predation on corals are relatively well known, their consequences for fish communities are less understood. We compared fish assemblages associated with 2 coral species, Pocillopora damicornis and Seriatopora hystrix, among 3 coral health categories: (1) live, (2) degraded and (3) dead colonies with recent algal growth. Categories 2 and 3 occur sequentially during the first few weeks following bleaching or crown-ofthorns starfish predation. The abundance of species with an obligate association with live coral differed among coral health categories. Average total abundance of all fish species was lowest in algalcovered colonies of both coral species and these assemblages were dominated by species that are not closely associated with live coral. Lower fish abundance on algal-covered colonies was largely due to the low number of small size classes (new recruits and juveniles). This study suggests that habitat health may play an important role in structuring coral-associated fish assemblages.
\end{abstract}

KEY WORDS: Disturbance · Coral reef fishes · Coral health · Coral association · Pocillopora damicornis $\cdot$ Seriatopora hystrix

\section{INTRODUCTION}

Coral reefs support a spectacular diversity of fishes by providing food, shelter and living space. A variety of natural (e.g. coral bleaching, predation by crown-ofthorns starfish) and anthropogenic (e.g. overfishing, sedimentation, pollution) disturbances are contributing to a worldwide decline in hard corals (Pandolfi et al. 2003). There is increasing evidence that these disturbances can have a substantial effect on the structure of fish assemblages associated with coral reefs (Jones et al. 2004, Munday 2004b). However, our knowledge about the susceptibility to disturbance for the majority of common reef fish species and the diverse communities they form is far from complete (Jones \& Syms 1998).

Coral reef fish species vary in the degree to which they are reliant on characteristics of the underlying substratum (Syms \& Jones 2000). Coral-associated fish communities comprise a variety of species, representing the full spectrum of coral dependency, from extreme habitat specialists (Munday 2001) to species with highly flexible habitat requirements (Guzman \& Robertson 1989). Species-specific differences in live coral dependence are likely to influence how fish assemblages respond to live coral loss (Munday 2004b). Fish species with a strong preference for, or an obligate association with, live coral are likely to decline in both abundance and diversity in response to increased mortality of their host corals (Shibuno et al. 1999). Degradation of live coral may also influence both the movement and recruitment of species that utilise non-living coral substrata, such as dead corals or rubble (Jones \& Syms 1998). Furthermore, seaweeds typically colonise recently disturbed habitats (Hughes 1994), thereby increasing the availability of benthic algal resources. An increase in algal resources generally results in an increase in both the abundance and 
diversity of herbivores, detritivores and mobile invertebrate feeding fishes (McClanahan et al. 2002). Despite the potential for both declines and increases in fish abundance, responses to the degradation and/or death of corals are poorly understood.

Understanding the life history traits of coral-associated fishes is integral to predicting the effects of live coral loss on fish assemblages (Jones \& McCormick 2002). Fishes that can move easily among habitat patches and are either not closely associated with corals or are able to utilise a variety of habitats may be less susceptible to localised degradation or coral loss (Guzman \& Robertson 1989, Pratchett et al. 2004). However, during early life history stages, a large proportion of coral reef fish species are associated with live coral (Jones et al. 2004) through their use of live colonies as a settlement cue (Öhman et al. 1998), food source (Harmelin-Vivien 1989) or shelter (Webster 2002). Consequently, reductions in live coral may exert a negative influence on both settlement and recruitment in a range of coral reef fishes (Booth \& Beretta 2002). Habitat-limited settlement and recruitment may therefore be an important process by which fish assemblages respond to habitat degradation (Jones et al. 2004).

In this study we examined whether there were differences in the fish assemblages associated with coral colonies in 3 distinct phases of health. We hypothesised that the nature and strength of association between individual species and live coral would determine how fish assemblages differed between live, degraded and algal-covered coral colonies.

\section{MATERIALS AND METHODS}

Sampling. The study was conducted in the lagoon at Lizard Island on the northern Great Barrier Reef $\left(14^{\circ} 40^{\prime} \mathrm{S}, 145^{\circ} 28^{\prime} \mathrm{E}\right)$. Data were collected during February to March 2004. Fish assemblages associated with individual coral colonies $\left(\sim 11000\right.$ to $\left.14000 \mathrm{~cm}^{3}\right)$ of Pocillopora damicornis and Seriatopora hystrix (Pocilloporidae) were surveyed at depths between 2 and $6 \mathrm{~m}$ on 3 large reef complexes within the lagoon (Bird Islet, Front Reef, Vicki's Reef). Both coral species form sturdy, compact colonies and are common throughout the Indo-Pacific on upper reef slopes exposed to strong wave action. On each reef complex, colonies were classed into 3 health categories: (1) live; (2) degraded, and (3) degraded with recent algal growth. These 3 categories represent the successive stages of coral health resulting from either bleaching or predation by crown-of-thorns starfish (Marshall \& Baird 2000). Colonies were surveyed simultaneously, and no colony was surveyed more than once during the study period.
A total of 1541 fish were recorded: 558 individuals from 67 Seriatopora hystrix colonies $(n=20$ live, 31 degraded and 16 algal covered colonies), and 983 individuals from 118 Pocillopora damicornis colonies ( $\mathrm{n}=37$ live, 45 degraded and 36 algal covered colonies).

Fish assemblages on each colony were initially surveyed from a distance of $3 \mathrm{~m}$ to minimise observer disturbance, after which the interior branches of the colony were examined for cryptic fish species. All fishes seen to directly utilise the colony were counted, identified to species and assigned to 1 of 3 ontogenetic categories: (1) 'recruit' (<1 mo on reef), (2) 'juvenile' (>1 to 4 mo on reef), and (3) 'adult' (Randall et al. 1997, G. P. Jones unpubl., www.fishbase.com). Coral colony volume $\left(\pi \times r^{2} \times h[\mathrm{~cm}]\right.$, where $r=$ radius and $h=$ height from base of coral) and coral health category were recorded.

Data analysis. There was no significant correlation between the density of fishes associated with different colony sizes within each coral species (Seriatopora hystrix: $\mathrm{r}^{2}=0.001, \mathrm{p}=0.7$; Pocillopora damicornis: $\mathrm{r}^{2}=$ $0.006, p=0.3$ ); therefore, all survey data within each coral species and coral loss category were combined. Non-parametric multivariate analysis of variance (NPMANOVA, Bray-Curtis dissimilarity matrices, Anderson 2001), were used to test whether population abundances within pooled ontogenetic categories differed among the 3 coral health categories, both within and between coral species. Significant differences in assemblage structure were analysed using similarity of percentages, SIMPER (Primer version 5). Specifically, we determined the contribution of each fish species to the average similarity within and between assemblages associated with individual coral colonies, both within and between coral species.

All fish species were categorised into functional groups based on feeding, shelter and settlementhabitat requirements to test whether the association with coral health categories differed among functional groups (Randall et al. 1997, M. Srinivasan pers. comm.). We used the following 5 functional groups: (1) obligate coral use (OBLIG: associated with live coral throughout ontogeny), (2) corallivorous (CORAL: both obligate and facultative coral feeders), (3) coral dwelling (DWELL: use live coral as shelter throughout ontogeny), (4) coral settling (SETTL: settle to live coral, no association as adults), and (5) others (OTHER: no strong association with live coral at any stage in the lifecycle). NPMANOVA was used to examine the structure of functional groups among the 3 coral health categories, within and between coral species. Significant differences among coral colonies in the number of functional groups were analysed using SIMPER analysis (similarity percentages) to identify species that con- 
tributed most to similarities within and dissimilarities between assemblages.

Patterns in the diversity of functional groups associated with different coral health categories were compared using distribution-free randomisation tests in ECOSIM (Gotelli \& Graves 1996). Diversity was calculated using rarefaction, which estimated the expected richness and associated variance of random sub samples of each functional group between coral health categories within each coral species.

We tested whether the abundance of distinct ontogenetic stages differed among the 3 coral health categories, both within and between each coral species, using NPMANOVA (using Bray-Curtis dissimilarity matrices). Significant differences were analysed using SIMPER analysis to identify species that contributed most to similarities within and dissimilarities between the fish assemblages associated with coral health categories.

\section{RESULTS}

\section{Live colonies}

There were significant differences between the structures of fish assemblages associated with live colonies of Seriatopora hystrix and Pocillopora damicornis (Table 1). Total abundance on P. damicornis colonies was significantly lower than on $S$. hystrix colonies, but $P$. damicornis fish assemblages were more diverse (Fig. 1). P. damicornis colonies were numerically dominated by both coral-dwelling planktivorous damselfishes (Pomacentridae) and non-coral associated, benthic-feeding wrasses (Labridae) (Fig. 2). In comparison, obligate coral-dwelling gobies (Gobiidae) numerically dominated $S$. hystrix colonies, and non-coral associated wrasses (Labridae) and damselfishes (Pomacentridae) and coral-dwelling planktivorous damselfishes (Pomacentridae) were abundant (Fig. 2). Coralli-

Table 1. Seriatopora hystrix and Pocillopora damicornis. Nonparametric multivariate analysis of variance (NPMANOVA) comparisons between fish assemblages associated with live coral colonies, live and degraded colonies, and degraded and algal-covered colonies of 2 coral species. Data are p-values. ${ }^{*} \mathrm{p} \leq 0.05$

\begin{tabular}{|c|c|c|c|}
\hline $\begin{array}{l}\text { Coral health } \\
\text { category }\end{array}$ & $\begin{array}{l}\text { S. hystrix vs. } \\
\text { P. damicornis }\end{array}$ & S. hystrix & P. damicornis \\
\hline Live & $0.0002^{*}$ & & \\
\hline $\begin{array}{l}\text { Live vs. } \\
\text { degraded }\end{array}$ & & $0.02^{*}$ & 0.1 \\
\hline $\begin{array}{l}\text { Degraded vs. } \\
\text { algal-covered }\end{array}$ & & $0.001^{*}$ & $0.0002^{*}$ \\
\hline
\end{tabular}

vores (Chaetodontidae) and coral settlers (Labridae, Pomacentridae) were present in low numbers on $P$. damicornis but were absent from S. hystrix (Fig. 2).

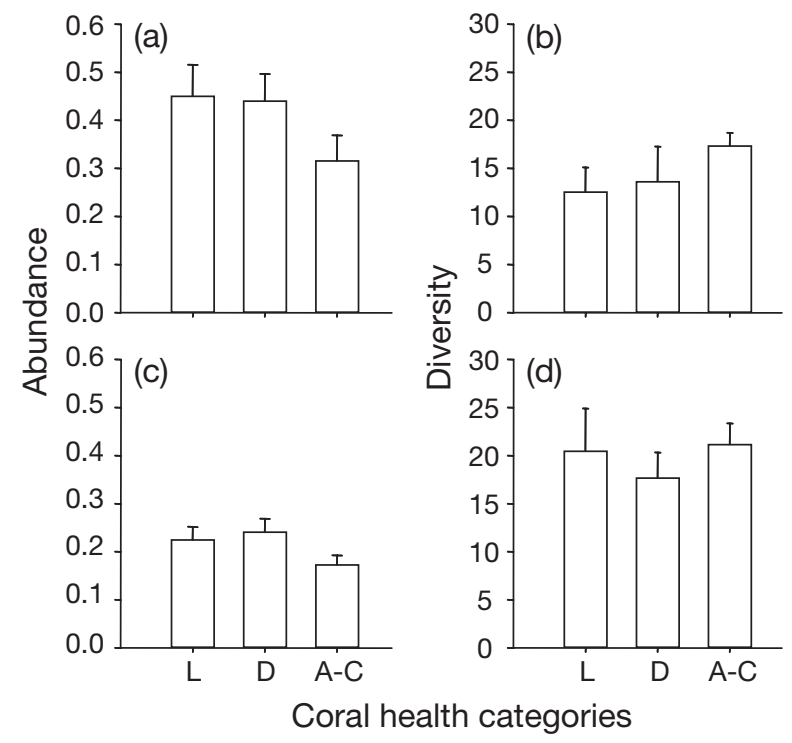

Fig. 1. (a,b) Seriatopora hystrix and (c,d) Pocillopora damicornis. Relationship between coral health (L: live, D: degraded, A-C: algal-covered) and average species $(a, c)$ total abundance per colony $(+\mathrm{SE})$ and $(\mathrm{b}, \mathrm{d})$ diversity per colony $(+95 \%$

CI) of fish assemblages on colonies of 2 coral species

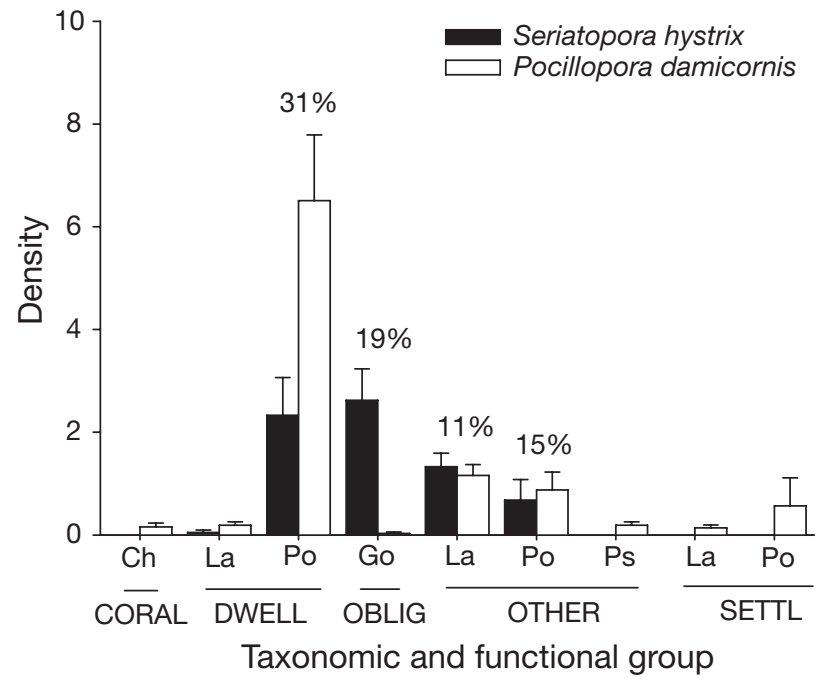

Fig. 2. Seriatopora hystrix and Pocillopora damicornis. Average density of ind. per colony (mean + SE) and the contribution of taxonomic and functional groups to the average dissimilarity between fish assemblages associated with live colonies of 2 coral species. Taxonomic groups - Ch: Chaetodontidae, La: Labridae, Po: Pomacentridae, Go: Gobiidae, Ps: Pseudochromidae. Functional groups - CORAL: corallivorous species (both obligate and facultative); DWELL: species dwelling on live coral; OBLIG: species that are obligate coral users; OTHER: species with no association with live coral; SETTL: species that settle to live coral. Percentages above bars: families contributing $>10 \%$ to dissimilarity 


\section{Live versus degraded colonies}

There were no significant differences in fish total abundance or diversity between live and degraded colonies within each coral species (Fig. 1). However, assemblage structure differed between live and degraded colonies for Seriatopora hystrix, but not Pocillopora damicornis (Table 1). For S. hystrix colonies, there was a greater abundance of coral-dwelling species (mainly planktivorous damselfish - Pomacentridae) in degraded colonies (Fig. 3a) and a low overall abundance of juvenile stages (Table 2). In contrast, for $P$. damicornis there were fewer non-coral associates (mainly benthic feeding wrasses-Labridae) and coral-associated species (coral dwelling damselfishes and corallivores - Pomacentridae and Chaetodontidae, respectively) on degraded colonies compared to live colonies (Fig. 3b).

\section{Degraded versus algal covered colonies}

Total abundance was lower on algal-covered colonies (Fig. 1) and assemblage structure differed between degraded and algal-covered colonies of both coral species (Table 1). For both corals, algal-covered colonies had fewer coral-dwelling fish species (predominantly planktivorous damselfishes - Pomacentridae) and greater numbers of non-coral associated species (primarily benthic-feeding wrasses, damselfishes - Pomacentridae - and blennies - Blenniidae) (Fig. 4). Obligate coral dwellers (Gobiidae) were absent from algal-covered colonies of Seriatopora hystrix (Fig 4a), and corallivores (Chaetodontidae) were absent from algal-covered colonies of Pocillopora damicornis (Fig. 4b). There was a low abundance of coralsettling species on degraded and algal-covered colonies of both coral species (Fig. 4). In addition, there were significant differences in the abundance of different ontogenetic stages between degraded and algalcovered colonies of both coral species (Table 2): recruits were absent from, and juveniles were present in very low numbers on algal-covered colonies of $S$. hystrix, and both juvenile and adult stages were present in low numbers on algal-covered $P$. damicornis colonies.

\section{DISCUSSION}

Although there is little consensus on the degree to which fish assemblages are reliant on characteristics of the underlying substratum (Jones \& Syms 1998), we found that the abundance, diversity, size structure and functional groups of coral-associated fish assemblages differed among live, degraded, and algal-covered

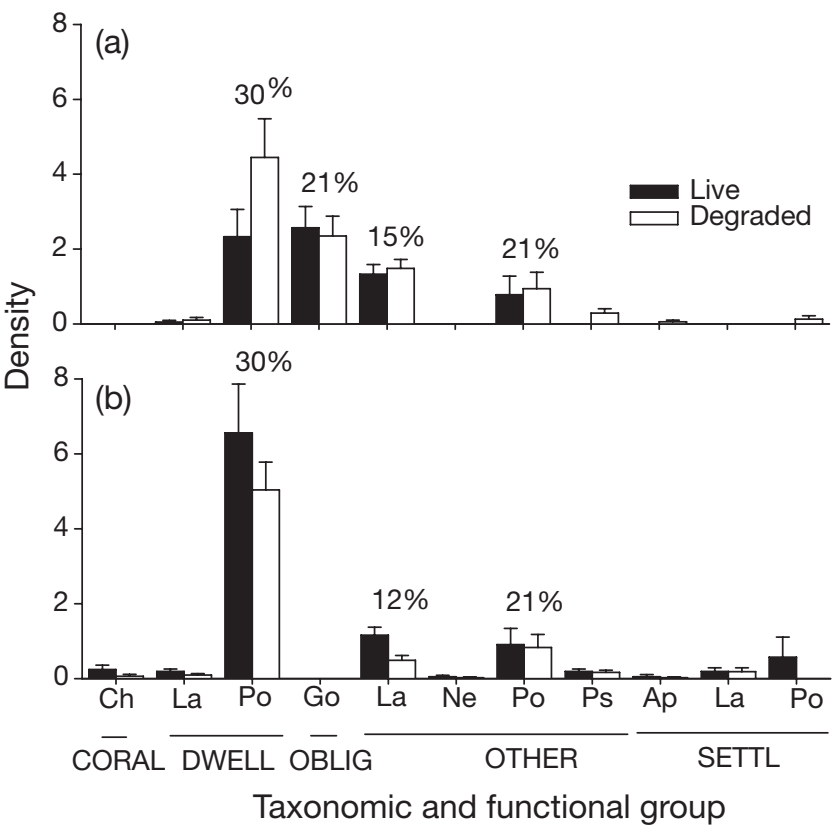

Fig. 3. Seriatopora hystrix and Pocillopora damicornis. Average density of ind. per colony (mean $+\mathrm{SE}$ ) and the contribution of taxonomic and functional groups to the average dissimilarity between fish assemblages associated with live and degraded colonies of 2 coral species: (a) $S$. hystrix and (b) $P$. damicornis. Taxonomic groups $-\mathrm{Ch}$ : Chaetodontidae, La: Labridae, Po: Pomacentridae, Go: Gobiidae, Ne: Nemipteridae, Ps: Pseudochromidae. Functional groups-CORAL: corallivorous species (both obligate and facultative); DWELL: species dwelling on live coral; OBLIG: species that are obligate coral users; OTHER: species with no association with live corali SETTL: species that settle to live coral. Percentages above bars: families con-tributing $>10 \%$ to dissimilarity

Table 2. Seriatopora hystrix and Pocillopora damicornis. Nonparametric multivariate analysis of variance (NPMANOVA) of comparison of ontogenetic fish-assemblage structure associated with live, degraded and algal-covered colonies of 2 coral species. Data are p-values. ${ }^{*} \mathrm{p} \leq 0.05$

\begin{tabular}{|llllll|}
\hline \multirow{2}{*}{$\begin{array}{l}\text { Ontogenetic } \\
\text { stage }\end{array}$} & \multicolumn{2}{c}{$\begin{array}{c}\text { Live vs. hystrix } \\
\text { degraded }\end{array}$} & $\begin{array}{c}\text { Degraded } \\
\text { vs. algal }\end{array}$ & $\begin{array}{c}\text { Live vamicornis } \\
\text { degraded }\end{array}$ & $\begin{array}{c}\text { Degraded } \\
\text { vs. algal }\end{array}$ \\
\hline Recruit & 0.2 & $0.0004^{*}$ & 0.5 & 0.4 \\
Juvenile & $0.02^{*}$ & $0.01^{*}$ & & 0.1 & $0.0002^{*}$ \\
Adult & 0.9 & 0.500 & & 0.1 & 0.07 \\
\hline
\end{tabular}

coral colonies. Degraded colonies of both coral species had lower numbers of corallivores than live colonies, whereas non coral-associated fishes numerically dominated algal-covered colonies. However, in contrast to previous studies (e.g. Hughes 1994), fish assemblages on algal-covered colonies were not more diverse than those on degraded or live coral colonies. Lower total abundance of fishes on algal-covered colonies was primarily due to the low abundance of a small subset of planktivorous damselfishes (e.g. predominantly Poma- 


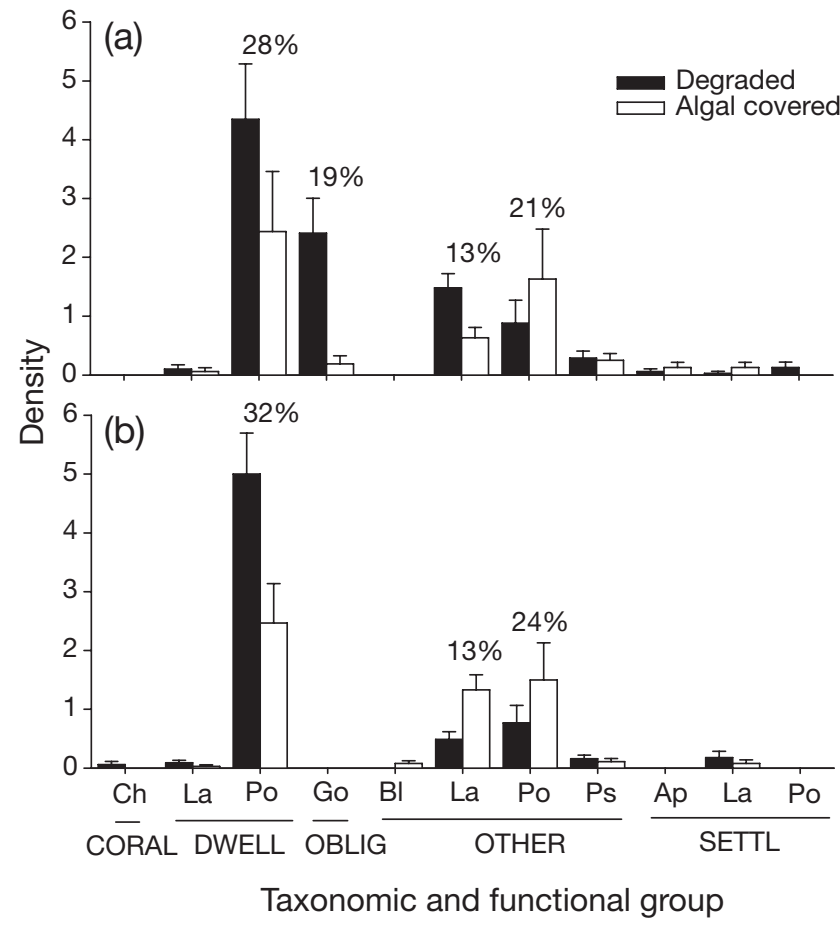

Fig. 4. Seriatopora hystrix and Pocillopora damicornis. Average density of ind. per colony (mean $+\mathrm{SE}$ ) and contribution of taxonomic and functional groups to average dissimilarity between fish assemblages associated with degraded and algalcovered colonies of 2 coral species: (a) $S$. hystrix and (b) $P$. damicornis. Taxonomic groups - Ch: Chaetodontidae, La: Labridae, Po: Pomacentridae, Go: Gobiidae, Bl: Blenniidae, Ps: Pseudochromidae, Ap: Apogonidae. Functional groupsCORAL: corallivorous species (both obligate and facultative); DWELL: species dwelling on live coral; OBLIG: species that are obligate coral users; OTHER: species with no association with live coral ${ }_{i}$ SETTL: species that settle to live coral. Percentages above bars: fami-lies contributing $>10 \%$ to dissimilarity

centrus moluccensis) that numerically dominated assemblages associated with live colonies of both coral species, and that typically form numerically abundant, mixed-aged groups on small coral colonies on IndoPacific coral reefs (Brunton \& Booth 2003). In the present study, planktivorous damselfishes were abundant on both live and degraded coral colonies, but were much less abundant on algal-covered colonies. Consequently, although the proportion of benthic feeders was greater on algal-covered colonies than on live and degraded colonies, the lower abundance of planktivorous damselfishes was the key reason overall abundance was lower on algal-covered colonies.

Significant differences in the composition of fish assemblages, at both taxonomic and functional levels, were observed both between coral species and coral health categories. Numerous studies have shown that the local-scale abundance of coral-associated reef fishes is correlated with specific biological or structural characteristics of corals (Munday 2000, Holbrook et al.
2002). Differences in the local-scale distribution of coral species may have a substantial effect on both the abundance and diversity of fish assemblages (Holbrook et al. 2000). As there are important differences in the susceptibility to degradation and ability to recover from disturbance among corals (Baird \& Marshall 2002), differences in the use of specific coral species may influence the extent to which fish assemblages are affected by coral degradation.

We observed lower numbers of newly settled fishes and juveniles on algal-covered colonies than on live and degraded colonies. Although previous studies have suggested that the loss of live coral may have demographic consequences for coral-associated fishes (Jones \& McCormick 2002), there has been little empirical evidence to support this idea (but see Booth \& Beretta 2002, Jones et al. 2004). Many coral reef fishes exhibit distinct patterns of habitat use at settlement and throughout their juvenile stage (Booth \& Wellington 1998). In the Indo-Pacific, as many as 60\% of coral reef fish species appear to associate with live coral during the early stages of their lifecycles (Jones et al. 2004). Clearly, with this level of reliance on live coral, the loss of the live coral could exert a negative influence on settlement and postsettlement movement in a range of coral reef fish species (Lewis 1998). Fluctuations in the availability of suitable habitat for a range of species may be an important process in driving local population dynamics (Jones \& Syms 1998). If live coral loss results in decreased settlement and thus lower numbers of new recruits and juveniles of some species, lasting changes in the local-scale composition of fish communities may result, including changes in species composition (Syms \& Jones 2000, Jones et al. 2004), trophic structure (Lewis 1998), and size structure (Munday 2004b).

Partial mortality of coral is a dominant feature within degraded habitat landscapes (Connell et al. 1997, Baird \& Marshall 2002). In the present study, degraded coral colonies consisted of up to $30 \%$ live coral cover. Degraded colonies of Seriatopora hystrix supported significant numbers of obligate coral-dwelling gobies. Coraldwelling gobies comprise a number of species that spend most of their adult life within the confines of a single live coral colony (Munday 2000, Munday et al. 2001), and depend on the colony for shelter and sites for reproduction (Munday 2002). Although the complete loss of live coral dramatically reduces the abundance of these fishes (Munday et al. 2001, Munday 2004b), our study demonstrates that partial mortality of the host colony provides enough suitable habitat for individuals to remain within the confines of the colony. The extremely limited mobility of most gobies (Nilsson et al. 2004), coupled with increased predation risk during movement (Stewart \& Jones 2001) and strong interspecific competition for suit- 
able habitat (Munday 2001, 2004a) may reduce any potential benefit of emigrating to a healthier colony and may explain why these obligate coral-dwelling fishes remain in partially degraded coral colonies.

There is increasing evidence that the reductions in live coral cover associated with a variety of both anthropogenic and natural disturbances may have profound effects on the structure of coral-associated fish assemblages. In the present study we observed differences in total abundance, species diversity, the abundance of particular functional groups, and the size structure of fish assemblages amoung live, degraded, and algal-covered coral colonies. This study suggests that the health of corals plays an important role in structuring associated fish assemblages, and that the specific effects of coral degradation on fish communities will depend on the coral species and the taxonomic and functional composition of its associated fish assemblage.

Acknowledgements. This project was supported by Australian Coral Reef Society and Great Barrier Reef Marine Park Authority grants to D.A.F., a James Cook University Merit Research Grant to M.I.M. and an ARC Discovery grant to G.P.J. Many thanks to L. Peacock for invaluable field assistance and the staff of Lizard Island Research Station for their field support.

\section{LITERATURE CITED}

Anderson MJ (2001) A new method for non-parametric multivariate analysis of variance. Aust Ecol 26:32-46

Baird AH, Marshall PA (2002) Mortality, growth and reproduction in scleractinian corals following bleaching on the Great Barrier Reef. Mar Ecol Prog Ser 237:133-141

Booth DJ, Beretta GA (2002) Changes in a fish assemblage after a coral bleaching event. Mar Ecol Prog Ser 245: 205-212

Booth DJ, Wellington G (1998) Settlement preferences in coral-reef fishes: effects on patterns of adult and juvenile distributions, individual fitness and population structure. Aust J Ecol 23:274-279

Brunton BJ, Booth DJ (2003) Density and size dependent mortality of a settling coral-reef damselfish (Pomacentrus moluccensis Bleeker). Oecologia 137:337-384

Connell JH, Hughes TP, Wallace CC (1997) A 30-year study of coral abundance, recruitment, and disturbance at several scales in space and time. Ecol Monogr 67:461-488

Gotelli NJ, Graves GR (1996) Null models in ecology. Smithsonian Institution Press, Washington, DC

Guzman HM, Robertson DR (1989) Population and feeding responses of the corallivorous pufferfish Arothron meleagris to coral mortality in the eastern Pacific. Mar Ecol Prog Ser 55:121-131

Harmelin-Vivien ML (1989) Implications of feeding specialization on the recruitment processes and community structure of butterflyfishes. Environ Biol Fish 25:101-110

Holbrook SJ, Forrester GE, Schmitt RJ (2000) Spatial patterns in abundance of a damselfish reflect availability of suitable habitat. Oecologia 122:109-120

Holbrook SJ, Brooks AJ, Schmitt RJ (2002) Variation in structural attributes of patch-forming corals and in patterns of abundance of associated fishes. Mar Freshw Res 53: 1045-1053

Hughes TP (1994) Catastrophes, phase shifts, and large-scale degradation of a Caribbean coral reef. Science 265: $1547-1551$

Jones GP, McCormick MI (2002) Numerical and energetic processes in the ecology of coral reef fishes. In: Sale PF (ed) Coral reef fishes: dynamics and diversity in a complex ecosystem. Academic Press, San Diego, CA, p 221-238

Jones GP, Syms C (1998) Disturbance, habitat structure and the ecology of fishes on coral reefs. Aust J Ecol 23:287-297

Jones GP, McCormick MI, Srinivasan M, Eagle JV (2004) Coral decline threatens fish biodiversity in marine reserves. Proc Natl Acad Sci USA 101:8251-8253

Lewis AR (1998) Effects of experimental coral disturbance on the population dynamics of fishes on large patch reefs. J Exp Mar Biol Ecol 230:91-110

Marshall PA, Baird AH (2000) Bleaching of corals on the Great Barrier Reef: differential susceptibilities among taxa. Coral Reefs 19:155-163

McClanahan TR, Maina J, Pet-Soede L (2002) Effects of the 1998 coral mortality event on Kenyan coral reefs and fisheries. Ambio 31:543-550

Munday PL (2000) Interactions between habitat use and patterns of abundance in coral-dwelling fishes of the genus Gobiodon. Environ Biol Fish 58:355-369

Munday PL (2001) Fitness consequences of habitat use and competition among coral-dwelling fishes. Oecologia 128: 585-593

Munday PL (2002) Does habitat availability determine geographical-scale abundances of coral-dwelling fishes? Coral Reefs 21:105-116

Munday PL (2004a) Competitive coexistence of coraldwelling fishes: the lottery hypothesis revisited. Ecology 85:623-628

Munday PL (2004b) Habitat loss, resource specialization, and extinction on coral reefs. Global Change Biol 10: 1642-1647

Munday PL, Jones GP, Caley MJ (2001) Interspecific competition and coexistence in a guild of coral-dwelling fishes. Ecology 82:2177-2189

Nilsson GE, Hobbs J, Munday PL, Ostlund-Nilsson S (2004) Coward or braveheart: extreme habitat fidelity through hypoxia tolerance in a coral-dwelling goby. J Exp Biol 207: 33-39

Öhman MC, Munday PL, Jones GP, Caley MJ (1998) Settlement strategies and distribution patterns of coral-reef fishes. J Exp Mar Biol Ecol 225:219-238

Pandolfi JM, Bradbury RH, Sala E, Hughes TP and 8 others (2003) Global trajectories of the long-term decline of coral reef ecosystems. Science 301:955-958

Pratchett MS, Wilson SK, Berumen ML, McCormick MI (2004) Sub-lethal effects of coral bleaching on an obligate coral feeding butterflyfish. Coral Reefs 23:352-356

Randall JE, Allen GR, Steene RC (1997) Fishes of the Great Barrier Reef and Coral Sea. University of Hawaii Press, HI

Shibuno T, Hashimoto K, Abe O, Takada Y (1999) Short-term changes in the structure of a fish community following coral bleaching at Ishigaki Island, Japan. Galaxea 1:51-58

Stewart BD, Jones GP (2001) Associations between the abundance of piscivorous fishes and their prey on coral reefs: implications for prey-fish mortality. Mar Biol 138:383-397

Syms C, Jones GP (2000) Disturbance, habitat structure, and the dynamics of a coral-reef fish community. Ecology 81: 2714-2729

Webster MI (2002) Role of predators in the early post-settlement demography of coral-reef fishes. Oecologia 131:52-60 